\title{
Environmental treaties' impact on the environment in resource-rich and non-resource-rich countries
}

\begin{abstract}
This study examines the impact of environmental treaties on the environment across 74 countries: 50 resourcerich and 24 non-resource-rich countries. Using data spanning over 35 years, we find a negative and significant association between environmental treaties and environmental quality in resource-rich countries. On the contrary, we find environmental treaties positively and significantly affect the environment in non-resource-rich countries. Our results suggest that the environmental treaties signed by resource-rich countries may lead them to achieve sustainable development growth by 2030 . Therefore, our results extend the environment literature and inform policymakers of the need to pay attention to the effects of signing environmental treaties on environmental protection.
\end{abstract}

Keywords: Environmental treaties; Environment; FDI; Trade; Resource-rich; Non-resource-rich

\section{Introduction}

Although countries adopt environmental regulation policies to protect the environment, with the improvements in international urbanization and globalization, no countries exist in isolation. Among countries, there exist relations in terms of trade, international issues, and treaties. As such, reducing global warming, on which this study focuses, has become a global issue. Thus, there is a need for environmental treaties to ensure that global environmental degradation is drastically reduced. Environmental treaties make environmental protection and quality an issue to be addressed globally so that the required environmental goals can be reached. According to Kanie (2007), environmental treaties are established when two countries agree to protocols, conventions acts, arrangements, and agreements bound by international law, allowing them to reach an environmental goal. This constitutes attempts to curb environmental degradation resulting from industrial activities and greenhouse gas (GHG) emissions. There are various types of environmental treaties, such as the Convention of Biological Diversity, Law of the Sea, Ozone Treaties, Stockholm Convention on Persistent Organic Pollutants, Framework Convention on Climate Change, and the Basel Convention on the Control of Transboundary Movements of Hazardous Wastes and Their Disposal. Environmental treaties are also known as multilateral environmental agreements (MEAs) when they involve three or more countries. An example of an MEA is the Convention of Biological Diversity, which was finalized on June 5th, 1992, at the Earth Summit in Rio de Janeiro and entered into force on December 29th, 1993. The Convention of Biological Diversity has three main goals-the conservation of biological diversity, the sustainable use of its components, and the fair and equitable use of shared resources - which aim to develop strategies for national conservation and sustainable use of biological diversity among the participating countries. 
Based on the abundance of natural resources, countries can be classified as resource-rich and nonresource-rich. Resources include oil, timber, natural gas, and coal, considered as more valuable than commodities such as uranium, silver, and phosphate, because of their high value in terms of reserves and demand. Thus, Wall Street identified Russia as the world's most prosperous country based on the possession of natural resources, with a total revenue of $\$ 75.7$ trillion, oil reserves of approximately 1,680 trillion cubic ft ( $\$ 19$ trillion), and timber reserves of approximately \$28.4 trillion. The United States ranks second among resourcerich countries, excluding its oil reserves — which did not make the top 10, with a revenue value of $\$ 45$ trillionnatural gas reserves worth $\$ 3.1$ trillion, and timber reserves worth $\$ 10.9$ trillion. Following the United States on the list is Saudi Arabia who has almost $20 \%$ of the world's oil reserves, estimated to be 266.7 billion barrels (\$31.5 trillion); natural gas reserves (\$2.9 trillion), as well as timber, and a total revenue of \$34.4 trillion. Furthermore, Canada is the fourth resource-richest country, with oil and timber reserves of \$21 trillion and $\$ 11.3$ trillion, respectively, with a total revenue of $\$ 33.2$ trillion. As the fifth most prosperous country in natural resources, Iran has oil reserves worth \$16.1trillion, approximately 136.2 billion barrels, and natural gas reserves worth \$11.2 trillion. China's riches in natural resources are heavily based on coal and other rare earth resources, which is evident from the fact that its oil and timber (at \$6.5 trillion) reserves are not among the top 10 resources. This is also true for Brazil, whose $\$ 17.5$ trillion resource revenue comes from gold, uranium, and timber. Australia's natural resources wealth comes from coal, timber, copper, and iron ore, with the country accounting for approximately $14.3 \%$ of the global supply of gold and $46 \%$ that of uranium. With a total revenue value of $\$ 15.9$ trillion, Iraq's most significant resource is oil, with reserves worth approximately $\$ 13.6$ trillion. Venezuela, the least resource-rich country in the top 10, has oil reserves of \$99.4 trillion barrels (worth \$11.7 trillion) and natural gas reserves of $\$ 1.9$ trillion. Meanwhile, these resource-rich countries have total revenues that are relatively high, and as their natural gas (fossil fuel, coal, and renewable energy) consumption increases, it can increase their carbon emissions, damaging the environment. This is why some scholars, although few, have reached an agreement on these issues. For instance, renewable energy contributes less to carbon emissions than fossil fuel energy consumption in the European Union (UN) countries. This implies that a shift in the energy mix from fossil fuels to renewable energies will reduce GHGs (Bölük \& Mert, 2014). Likewise, renewable energy is not only economically but also ecologically beneficial because of its almost zero carbon emissions. In addition, nuclear energy does not contribute to a reduction in carbon emissions as much as renewable energy. To curb global warming, it is essential to develop and expand renewable energy sources instead of nuclear energy consumption. Contrary to concerns that the cost of renewable energy may negatively affect economic growth, renewable energy consumption contributes to economic growth while alleviating the pressure of environmental concerns (Jin \& Kim, 2018).

Furthermore, Pao and Tsai (2020) estimate that a two-way causal relationship exists between the consumption of energy and (1) carbon emissions and (2) national output, both in the short and long run. Therefore, in reducing carbon emissions to prevent the adverse effects of emissions on economic growth, it is important to increase the supply of energy investments and energy efficiency while improving energy conservation policies to reduce energy wastage (Pao \& Tsai, 2010). 
To the best of our knowledge, no empirical study has investigated environmental treaties and their effects on carbon emissions and environmental degradation. This study investigates these effects and examines who is affected by these treaties: resource-rich countries or non-resource-rich countries.

\section{Literature Review}

The nexus among macroeconomic variables and the quality of the environment has attracted significant attention in the last decade. Several studies have attempted to investigate the effect of energy consumption on economic growth, environmental regulation, foreign direct investment (FDI), and carbon emissions, trade openness, and the environment, and the relationship between trade, carbon dioxide $\left(\mathrm{CO}_{2}\right)$ emissions, FDI, and energy consumption (Adedoyin et al., 2020; Adedoyin \& Bekun, 2020).

\subsection{Environmental Treaties, Energy Consumption, and Environmental Quality}

The existing measures and regulations to control and reduce pollution have not been achieved. In addition, the impact of FDI on the environment is negative and significant, proving the absence of pollution-haven hypotheses for China and indicating that environmental regulation can only be effective when policies control FDI (Hao et al., 2018 and Li et al., 2020a).

Similarly, the relocation of firms is subtle. It is more likely to be influenced by government environmental laws in locations where pollution abatement seems high, making relocations common and consistent with the laws in China's Jiangsu province. This implies that local governments can use environmental objectives to achieve economic objectives. Equitable and comprehensive policy design protecting the environment is essential for favorable environmental outcomes. Therefore, it is important to not only ensure that environmental regulations are introduced to protect the country's environment but specific and compelling environmental laws guiding local governments toward protecting the environment will aid in regulating the polluting manufacturing industry (Yang et al., 2018).

On the other hand, as regards the environment, it is not only pollution-haven hypotheses that can be examined but also the rate of tourist arrivals, which may influence environmental performance. However, these effects differ by country and province due to differences in laws governing tourism and environmental policies. For instance, tourism exerts a significant positive effect on environmental pollution for Malaysia, while the reverse is true for Thailand and Singapore; this may be due to differences in their environmental, tourism, or trade laws. However, prudent public policy will aid sustainable economic growth and development when the governments of host countries ensure socially and environmentally responsible tourism industries (Azam et al., 2018).

Additionally, in the short run, both pollution-haven hypotheses and EKC exist, while in the long run, the former is absent. Therefore, energy consumption is an important determinant of environmental degradation due to energy generation sources that are non-renewable and carbon-oriented. Governments need to come together through treaties and investment in $R \& D$ to mitigate environmental challenges. This can be done with 
the initiation of environment-friendly regulations to minimize environmental degradation. Deliberate efforts by statistical environmental institutions ensure first-hand compilation and analysis of environmental information to quickly track the progress toward the projected sustainability and objectives (Waqih et al., 2019).

Whether or not an increase in countries' economic and financial development increases environmental degradation is not a topic of debate. This is because economic development is associated with trade openness, globalization, and tourism, which increase industrial activities, thereby increasing degradation. However, increased economic and financial development contributes to a reduction in environmental degradation. Further, attempts to reduce $\mathrm{CO}_{2}$ emissions require financial liberalization and openness. This will contribute to the attraction of R\&D-related FDI, which will aid the reduction in environmental degradation (Tamazian et al., 2009).

\subsection{Trade, Economic Growth, FDI, and Emissions}

Trade is an essential aspect of economic activities and economic development; however, countries' high levels of trade openness often result in environmental issues if not appropriately managed. Significant long-run relationships exist among trade openness, CO2 emissions, and economic growth. Trade openness affects the quality of the environment globally and in middle-income countries: there is a two-way relationship between trade openness and carbon emissions but a one-way causality running from the degree of trade openness to $\mathrm{CO}_{2}$ emissions (Shahbaz et al., 2017). In addition, there is a significant (U-shaped) relationship between income and carbon emissions, that is, as income increases, carbon emissions and environmental pressure increase to a certain level and then begin to decline, as stated by the EKC hypotheses. Energy exerts a positive influence on carbon emissions, implying increased carbon emissions with an increase in energy consumption. Both trade openness measures are negatively associated with carbon emissions in OECD countries in the long run (Gozgor, 2017). Long-run relationships exist among particulate matter (PM10) emissions, trade openness, and economic growth. In addition, an increase in the level of trade openness leads to environmental pressure and degradation. However, the effect of trade on emissions differs by country, as trade openness has a soothing effect on emissions in high-income countries. In contrast, its effect is harmful in middle-low income countries. This is in line with the popular opinion that rich countries dump their pollution on poor countries (Le et al., 2016).

FDI emerged as a result of globalization and is necessary for countries to become engaged in the global space. It contributes to a nation's GDP and economic development, particularly when developing countries host large firms. However, countries' carbon emissions seem to increase with increased foreign investment, and this is due to the increase in industrial activities. Energy consumption, FDI inflows and outflows, $\mathrm{CO}_{2}$ emissions, and capital play important and relevant roles in economic growth. In attempts to achieve economic growth, it is vital to make prudent policies to encourage clean energy. This will encourage foreign investors to invest and promote economic growth (Muhammad \& Khan, 2019). Thus, FDI will not contribute to the increase in carbon emissions, in contrast to popular opinion (Demena \& Afesorgbor, 2020).

Carbon emissions resulting from energy consumption and other industrial activities have contributed to environmental pollution and degradation, thereby reducing environmental quality. Therefore, in recent times, a 
shift from the consumption of fossil fuel types of energy, which are usually from non-renewable sources, has become imperative. Investigating the determinants of carbon emissions in the European Union, (Dogan \& Seker, 2016) asserted that renewable energy contributes to the reduction and mitigation of carbon emissions while non-renewable energy increases carbon emissions. Testing the causality, a two-way relationship exists between renewable energy and carbon emissions, which implies that renewable energy influences carbon emissions and vice versa. A one-way influence runs from income to carbon emissions, $\mathrm{CO}_{2}$ emissions to nonrenewable energy, and trade openness to $\mathrm{CO}_{2}$ emissions.

It is important to note that a clear understanding of the correlations between economic growth, energy consumption, and $\mathrm{CO}_{2}$ emissions is imperative to enable the government to implement energy-saving, strategize to ensure a reduction in carbon emissions, and reduce the impact of environmental degradation due to climate change (Wang et al., 2016). However, Sun et al. (2020) claim that low-emission technologies and emissions transfer behavior can also reduce emissions within supply chains. This provides new insight into the carbon emissions transfer behavior of enterprises. The interrelationships among trade, economic growth, and FDI are quite complex. This is because, in most cases, each variable either positively or negatively influences one another. For instance, in Mexico, the relationships among economic growth, the consumption of energy, and inflows of FDI are bidirectional, meaning that the activities associated with one variable affect the others. The same relationship exists between economic growth and energy consumption. In Indonesia, on the other hand, there is a one-way causal relationship between economic growth and FDI inflows as well as from FDI to energy consumption. However, in Nigeria, there exist bidirectional causal relationships between economic growth and energy consumption and between economic growth and FDI inflows. Further, there is a one-way causal relationship running from FDI inflows to energy consumption. In Turkey, two-way causal relationships exist among economic growth, energy consumption, and FDI inflows. Generally, a two-way causal relationship exists between E.G. and FDI and a one-way causal relationship from FDI to energy consumption (Lin \& Benjamin, 2018).

Trade, economic growth, FDI, and carbon emissions are essential issues every nation puts into consideration not only to prosper as a nation but also to promote its international presence. However, due to the adverse effect of carbon emissions, it is imperative to divert attention from fossil fuel consumption, that is, to improve labor productivity, economic diversification should be promoted, and over-dependence on the consumption of fossil fuel discouraged. A review of the literature shows that no empirical research has been conducted on the impact of environmental treaties on the environment. This study, however, attempts to investigate environmental treaties' impact on the environment: Who benefits from these treaties, resource-rich or non-resource-rich countries?

\section{Data and Model Specifications}

\subsection{Data source and description}

Our investigation comprises 74 countries for the period 1990-2014. The data were collected from the World Development Indicators database, except for the data on environmental treaties. The environmental treaties 
variable was computed as the number of environmental treaties in which a country participated from 1980 until 2015. Mathematically, the environmental treaties variable was the total number of environmental agreements or attendances a country had signed, as a percentage of the total number of environmental treaties registered at the United Nations Treaty Collection (2018) in a particular year. We also categorized countries as resource-rich and non-resource rich based on the US Energy Information Administration database (2019). $\mathrm{CO}_{2}$ emissions were measured in metric tons per capita (see Li et al. 2020b; Tawiah et al. 2020; Zakari and Tawiah 2019), while FDI inflow was measured by FDI inflow as a proportion of GDP, and energy consumption was measured in kilograms of energy use per capita of oil equivalent. Economic growth was measured by GDP at constant 2010 US\$; economic development was GDP per capita at constant 2010 US\$, and population was a country’s total population. The data availability guided our choice of control variables and time period.

\subsection{Model Specifications}

In recent times, researchers in energy and environmental economics have often used the Kaya identity as a model to determine the environmental impact of different factors (Taka et al. 2020; Yang et al. 2020; Engo 2019). The Kaya identity assumes that population growth, economic factors, energy technology, and the carbon emissions cycle predict the growth of carbon emissions. Therefore, the environmental impact model should include these factors (Engo 2019). Hence, one possible way to establish an environmental model is to assume that the impacts are driven by population, affluence, and technology, which is known as the IPAT equation.

Environmental impacts $=($ Population $) \times($ Affluence $) \times($ Technology $)$.

However, Brauch and Oswald (2009) argued that environmental impacts could be due to the effects of socio-economic interaction, environmental scarcity, degradation, and stress, or the impact of natural and human inducement on the earth. Beyond nature, Brauch and Oswald (2009) also find that societal outcomes (such as individual choice [survival dilemma] and societal response) and response policy by nations and international organizations can reshape the environmental impact. Brauch and Oswald (2009) developed a model known as the pressure, effect, impact, societal outcomes, and response (POISOR) model:

$$
P=E \times I \times S O \times R
$$

Here, the environmental impact "P" refers to the global environmental change, which is determined by effect "E," which refers to the socio-economic interaction, environmental scarcity, degradation, and stress. The impact "I" represents natural and human-induced earth impacts, while societal outcome "SO" indicates the individual choice (survival dilemma) and societal response. The "R" refers to response in terms of nations' policies and state and international political processes.

The IPAT for carbon emissions from the energy source is widely called the Kaya identity, and is more concrete than the IPAT (Taka et al. 2020; Yang et al. 2020; Engo 2019). Accordingly, we use the Kaya identity 
model to estimate the role of environmental treaties, energy consumption, economic growth, economic development, and population on $\mathrm{CO}_{2}$ emissions for the 74 resource-rich and non-resource-rich countries, as presented in equations (2), (3), and (4). Equation (2) represents ratios that are part of the Kaya Identity, and these factors showcase the relationship between $\mathrm{CO} 2$ emissions and its determinants.

$F=P \times \frac{G}{P} \times \frac{E}{G} \times \frac{F}{E}$

where the environmental impacts "F" represent carbon emissions, which are determined by "P," the population affluence expressed as GDP per person; "E," energy consumption expressed per unit of GDP; and carbon emissions, "F," expressed as energy consumption per unit. We extend both the IPAT equation and Kaya identity, as given by equations (2) and (3). In the equation, we incorporate the POISOR model, given by equation (4), in its simplified version in equation (5).

$$
C O_{2 i t}=P O P_{i t} \times \frac{G D P_{i t}}{P O P_{i t}} \times \frac{E D I_{i t}}{T E D_{i t}} \times \frac{E C_{i t}}{P C O_{i t}} \times \frac{E D_{i t}}{P O P_{i t}},
$$

simplified to

$\operatorname{InCO} \mathrm{O}_{2 i t}=\alpha_{0}+\alpha_{1} \operatorname{InEDI} I_{i t}+\alpha_{2} \operatorname{InEC_{it}}+\alpha_{3} \operatorname{InEG_{it}}+\alpha_{4} \operatorname{InED_{it}}+\alpha_{5} \operatorname{InPOP} P_{i t}+\varepsilon_{i t}$,

where " $\mathrm{CO}_{2}$ " represents $\mathrm{CO}_{2}$ emissions (which captures the environment); "EDI" and "EC" are environmental treaties and energy consumption, respectively; and "EG" captures economic growth through GDP growth as a proxy. Additionally, "ED" is economic development measured as GDP per capita and "POP" denotes population, measured by a country's total population in a given year. The country-specific indexes are "i," and "t," where "i" represents an individual country and "t" signifies the time. " $\varepsilon$ " is the error term.

\section{Results and Discussion}

\subsection{Preliminary investigation}

Table 1 presents the unconditional correlations for the sample of 74 countries, comprising 50 resource-rich countries and 24 non-resource-rich countries. The results confirm that $\mathrm{CO}_{2}$ emissions are positively related to environmental treaties, energy consumption, economic growth, economic development, and population in the 74 countries. These suggest that $\mathrm{CO}_{2}$ emissions are connected to these variables on a larger scale. Likewise, the results on resource-rich vs non-resource-rich countries reveal that in both types of countries, $\mathrm{CO}_{2}$ emissions are positively related to environmental treaties, energy consumption, economic growth, and economic development, but not to population, which shows no connection with $\mathrm{CO}_{2}$ emissions in the non-resource-rich countries. In summary, the correlation analysis suggests that $\mathrm{CO}_{2}$ emissions are positively associated with most of the variables under consideration, that is, environmental treaties, energy consumption, economic growth, economic 
development, and population, across all the panels, except that for non-resource-rich countries, populations show no significant relationship with $\mathrm{CO}_{2}$ emissions.

[Insert Table 1 - Unconditional correlations]

\subsection{Cross-sectional dependence (CD) - Cross-sectional augmented IPS (CIPS) test estimation}

Estimating the $\mathrm{CD}$ in panel data has become the norm. This helps us deviate from the traditional panel econometric approaches, which assumed no cross-sectional dependence in the data series. Nevertheless, this is not always the case, as most panel datasets exhibit CD. Therefore, the results obtained from such datasets are bound to include unpredictable outcomes. Therefore, we estimate CD or independence using Pesaran's (2004) CD estimator for the 74 countries comprising 50 resource-rich countries and 24 non-resource-rich countries.

The results of the $\mathrm{CD}$ analysis are presented in Table 2. The results for all the panels (i.e., full sample, resource-rich countries, and non-resource-rich countries) recommend the acceptance of the alternative hypothesis at the $1 \%$ or $5 \%$ significance level. Thus, we reject the null hypothesis of no cross-sectional independence. This indicates that our data series from 1980 to 2015 are cross-sectionally dependent.

[Insert Table 2 - Cross-sectional dependence (CD)]

Since we confirmed the presence of CD across the series, it became necessary to use a unit-root estimator that takes into account the CD. Thus, we use a CIPS panel unit root estimator that accounts for CD or independence. Specifically, we use Pesaran's (2007) CIPS test because of its novelty in considering CD, as observed in Table 2. Table 3 shows the results of the CIPS test. The results suggest evidence of non-stationarity for most of the variables in the three panels, except for environmental treaties and economic growth, which are stationary at the $1 \%$ significance level. In the resource-rich countries panel, we also find that economic growth is stationary at the $1 \%$ significance level. However, when taking the first-order difference, we find that all the variables become stationary, leading us to reject the null hypotheses of no stationary at the $1 \%$ or $5 \%$ significance level for all the samples and accept the alternative hypotheses. Therefore, we conclude that our variables are not stationary at levels but stationary at first difference.

[Insert Table 3 - Panel unit root test results]

\subsection{Multivariate analyses}

Previous studies (Chen et al. 2020; Destek 2020; Le and Ozturk 2020) use fixed effects and augmented mean group models, which cannot account for endogeneity in the model. Hence, the findings of these studies had some limitations for conducting an endogeneity test. Therefore, we aimed to explore the role of environmental treaties on $\mathrm{CO}_{2}$ emissions using a model that checks for endogeneity. To achieve the goals of this study, we utilize the system-generalized method of moments (S-GMM) to ascertain the short-run dynamic relationships 
among the series. The S-GMM enables us to account for the dynamic equilibrium within the models, and for endogeneity. The method targets specific linear and non-linear relationships among variables (Hensen 2001). In addition, S-GMM estimators are robust to failures of auxiliary distributional assumptions that are not needed to identify critical parameters (Hall et al. 2007). Therefore, the use of the S-GMM estimator improves precision and dramatically reduces the finite sample bias.

The results for S-GMM are presented in Table 4; they suggest that environmental treaties positively promote environmental quality in the full sample of 74 countries and in the resource-rich countries, as shown in columns 1 and 2. A $1 \%$ increase in the number of environmental treaties leads to a $\mathrm{CO}_{2}$ emissions reduction by nearly $152.0 \%$ in the 74 countries and $215.8 \%$ in the resource-rich countries, indicating that the many treaties these countries signed played an important role in improving the quality of their environment. This means that the countries who sign treaties are obliged to implement and commit to the agreement, which is likely to reduce $\mathrm{CO}_{2}$ emissions. This finding is partly consistent with that of Wang et al. (2016), who report that globalization has helped reduce $\mathrm{CO}_{2}$ emissions in developed countries, but contrary to that of Salahuddin et al. (2016), who show that globalization increases $\mathrm{CO}_{2}$ emissions.

On the contrary, the relationship between environmental treaties and $\mathrm{CO}_{2}$ emissions in non-resourcerich countries is positive and statistically significant: a $1 \%$ increase in the number of environmental treaties is linked with a $15.81 \%$ increase in $\mathrm{CO}_{2}$ emissions. Increasing the number of environmental treaties signed slightly harms the environment of non-resource-rich countries, particularly through $\mathrm{CO}_{2}$ emissions because of liberalization. Liberalization has caused the exportation of $\mathrm{CO}_{2}$ emissions from developed countries to nonresource-rich countries in the form of non-environmentally friendly technologies. This partly agrees with the findings of Wang et al. (2016), who show that globalization has helped reduce $\mathrm{CO}_{2}$ emissions in developed countries and increase $\mathrm{CO}_{2}$ emissions in developing countries. In contrast, Liu et al. (2020) find an inverted-U relationship between globalization and $\mathrm{CO}_{2}$ emissions.

The results also confirm that the lagged value of $\mathrm{CO}_{2}$ emissions negatively affects the environment in the three models: a $1 \%$ increase in this variable leads to a rise in $\mathrm{CO}_{2}$ emissions in the full sample (74 countries) by nearly $1.018 \%, 1.019 \%$ in resource-rich countries), and $0.933 \%$ in non-resource-rich countries. The percentage for non-resource-rich countries is slightly lower than that for the full sample and resource-rich countries, indicating that these countries' resource-based capacities prevent them from emitting $\mathrm{more}^{\mathrm{CO}_{2}}$ emissions.

The results for most of the control variables are consistent with the standard assumptions. For example, the impacts of energy consumption are only felt in non-resource-rich countries. They are negative: a $1 \%$ increase in energy consumption is linked to a $0.114 \%$ increase in $\mathrm{CO}_{2}$ emissions. This may be because nonresource-rich countries still use traditional energy sources such as fossil fuels, which increases $\mathrm{CO}_{2}$ emissions. The coefficient of economic growth proxies based on GDP growth is positive and statistically significant in all three models: a $1 \%$ increase in economic growth leads to an increase of approximately $1,369 \%$ in the $\mathrm{CO}_{2}$ emissions of the 74 countries, $2,055 \%$ in those of the resource-rich countries, and $66.24 \%$ in those of the nonresource-rich countries. The impact of economic development on the change in $\mathrm{CO}_{2}$ emissions is negative and positive for the full sample and non-resource-rich countries, respectively. Surprisingly, the impact of economic development on $\mathrm{CO}_{2}$ emissions in resource-rich countries is not significant. A $1 \%$ increase in economic 
development leads to a nearly $0.0914 \%$ reduction in $\mathrm{CO}_{2}$ emissions for the full sample, while it increases the $\mathrm{CO}_{2}$ emissions of non-resource-rich countries. Overall, the results show that resource-rich countries benefit from environmental treaties, while non-resource-rich countries suffer from such treaties, with their $\mathrm{CO}_{2}$ emissions increasing.

Insert Table 4 - Generalized method of moments (GMM)]

\subsection{Accounting for FDI and trade}

In the implementation of treaties, it is essential to consider foreign investment and trade because of their prime effects on the economy; thus, we investigate the extent to which FDI and trade may or may not change the influence of environmental treaties on the environment. Therefore, we specifically estimate their linkage for the full sample of 74 countries and for the subsamples of resource-rich and non-resource-rich countries. The findings are displayed in Table 5.

In the full sample, FDI and trade have a negative and statistically significant on $\mathrm{CO}_{2}$ emissions. A $1 \%$ increase in FDI and trade is linked with a $977.3 \%$ and $322.4 \%$ decrease, respectively, in the $\mathrm{CO}_{2}$ emissions of the 74 countries. The main reason may be that foreign investment in and trade with these countries are linked to investment and trading of renewable energy. This result is in line with that of Demena and Afesorgboh (2020), who demonstrated a negative relationship between FDI and environmental emissions in 65 countries. In contrast, the result disagrees with that of $\mathrm{Li}$ et al. (2019), who revealed a positive linkage between FDI and environmental performance in a sample of 40 countries. However, the coefficients of the moderating terms (environmental treaties)*FDI and (environmental treaties)*trade are positive; a 1\% increase in (environmental treaties)*FDI and (environmental treaties)*trade leads to an increase in the $\mathrm{CO}_{2}$ emissions of the 74 countries of nearly $17.79 \%$ and $6.141 \%$, respectively.

In columns 3 and 4, our empirical estimation shows that trade has a positive and statistically significant impact on the environment in resource-rich countries. A $1 \%$ increase in trade leads to an increase in $\mathrm{CO}_{2}$ emissions of approximately $328.5 \%$. In other words, resource-rich countries' policymakers should consider the substitution of traditional trading with green trading (renewable energy technologies and the like) to mitigate pollution. This finding is similar to that of Huang et al. (2019), who found a negative relationship between foreign trade and $\mathrm{CO}_{2}$ emissions in China. In contrast, the coefficient of FDI shows no significant relationship between trade and $\mathrm{CO}_{2}$ emissions. However, the coefficient of the moderating terms, (environmental treaties)*FDI, and (environmental treaties)*trade are positive; a $1 \%$ increase in (environmental treaties)*FDI and (environmental treaties) *trade leads to an increase in the $\mathrm{CO}_{2}$ emissions of resource-rich countries of nearly $15.15 \%$ and $7.752 \%$, respectively.

The results for the non-resource countries are presented in columns 5 and 6 . The results suggest that FDI, trade, and the moderating terms (environmental treaties)*FDI and (environmental treaties)*trade have no statistically significant impact on $\mathrm{CO}_{2}$ emissions. The estimation confirmed that FDI, trade, and the moderating terms (environmental treaties)*FDI and (environmental treaties)*trade do not improve the environment in nonresource-rich countries. 
The coefficients of the control variables are consistent with the standard assumptions. For example, the coefficient of economic development, proxied by GDP per capita, is positive and significant in most cases, implying that economic development is an essential factor that plays a significant role in achieving environmental quality. However, the coefficients of economic growth, population growth, and energy consumption are negative and significant, which indicates that they deteriorate the quality of the environment.

\section{Insert Table 5 - Moderating effects of foreign direct investment and trade]}

\subsection{Heterogeneous panel non-causality}

We investigated the short-run causalities between the variables, and the results are provided in Table 6. There is bidirectional causality among environmental treaties, energy consumption, economic development, population, and $\mathrm{CO}_{2}$ emissions in all three panels. This result is in accordance with those of previous studies, such as Chaabouni et al. (2016), Shahbaz et al. (2015), and Alam et al. (2011), while it is in contrast with the results of Mohmand et al. (2020) and Omri et al. (2014), who find a unidirectional relationship.

Further, our results show a unidirectional causality that runs from economic growth to $\mathrm{CO}_{2}$ emissions, but indicate no reverse causality in non-resource-rich countries. This finding is consistent with the results of Mohmand et al. (2020) and Omri et al. (2014). However, bidirectional causality between economic growth and $\mathrm{CO}_{2}$ emissions is confirmed in the full-sample panel and resource-rich countries. Overall, our causality test results imply that environmental treaties, economic growth, economic development, energy consumption, and population Granger-cause $\mathrm{CO}_{2}$ emissions in all the panels, except in non-resource-rich countries, where economic growth has no significant association with $\mathrm{CO}_{2}$ emissions.

[Insert Table 6 - Heterogeneous panel non-causality]

\section{Conclusion and policy recommendations}

Environmental treaties are important because they foster synergy to address the utmost critical environmental issues that are transboundary, such as carbon emissions, climate change, and protecting the oceans (Morin and Blouin, 2019). Despite the importance of environmental treaties, they have not drawn researchers' attention. Therefore, we attempted to investigate the effects of various variables, namely, environmental treaties, energy consumption, economic growth, economic development, and population on $\mathrm{CO}_{2}$ emissions in 74 countries, comprising 50 resource-rich countries and 24 non-resource-rich countries during 1980-2015. To this end, we conducted S-GMM and heterogeneous panel non-causality analyses to ascertain the effect of the aforementioned variables.

Our S-GMM estimations reveal the positive impact of environmental treaties on $\mathrm{CO}_{2}$ emissions in the 74 countries and resource-rich countries. In contrast, environmental treaties in non-resource-rich countries cause 
$\mathrm{CO}_{2}$ emissions to rise. Furthermore, we find that the relationship between energy consumption and $\mathrm{CO}_{2}$ emissions is positive and significant in the non-resource-rich countries, but not significant in the full sample and resource-rich countries. Economic growth and population exhibit positive effects on $\mathrm{CO}_{2}$ emissions in all the samples, while economic development a negative effect in the full sample but a positive one in the nonresource-rich countries. Surprisingly, no significant relationship was found in the case of resource-rich countries.

Moreover, the findings reveal that FDI and trade are the major factors affecting $\mathrm{CO}_{2}$ emissions. Simultaneously, the moderating terms (environmental treaties)*FDI and (environmental treaties)*trade indicate that their respective variables' combinations are most likely to increase $\mathrm{CO}_{2}$ emissions in the 74 countries. Similarly, in resource-rich countries, the moderating term (environmental treaties)*FDI shows that the corresponding combination of variables contributes to the rise in the $\mathrm{CO}_{2}$ emissions; however, the term (environmental treaties)*trade indicates that the corresponding combination of variables reduces $\mathrm{CO}_{2}$ emissions. However, foreign investment and trade in non-resource-rich countries do not influence environmental treaties and, consequently, $\mathrm{CO}_{2}$ emissions.

Based on our results, we make the following policy recommendations: First, the results show that environmental treaties positively affect the reduction of $\mathrm{CO}_{2}$ emissions in resource-rich countries. Therefore, the countries attracted by these treaties should focus on introducing high-tech content while formulating a strict environmental access system and preventing resource-intensive and pollution-intensive investment, following treaty agreements and adjusting the relevant preferential policies. We also find that the moderating term with FDI indicates a harmful effect on the environment. Therefore, a country's economic development efforts should not only consider the amount of FDI but should also pay attention to the quality of FDI and encourage enterprises to adopt the advanced technology of FDI companies through demonstration, competition, related personnel flow, and absorption. In addition, the relevant government departments should strengthen their supervision and management responsibilities and implement FDI policies to achieve low-carbon investment development.

Second, non-resource-rich countries should review their trading policies as soon as possible because environmental treaties increase their $\mathrm{CO}_{2}$ emissions. One possible reason for this surge in $\mathrm{CO}_{2}$ emissions is the transfer of carbon-based products from rich countries. Hence, it will be good for non-resource-rich countries to halt the carbon-based product transfer to their region. One possible way to achieve this is through carbon-based tax and incentives; the government can also shape the carbon trading within their region. It is also important to encourage the use of clean and renewable energy and make full use of nuclear, wind, solar, and tidal energy, and other new energy sources to establish a long-term mechanism of renewable and clean energy development, promotion, and application.

Third, both resource-rich and non-resource-rich countries should ultimately optimize their industrial structure by adopting existing scientific research systems and science and technology policies. By focusing on the development and utilization of new technologies to enhance their industrial energy efficiency will help to reduce their $\mathrm{CO}_{2}$ emissions. The related government departments should raise the price of energy through 
energy taxes to encourage firms to apply high tech solutions to reduce their energy consumption in the industry. At the same time, countries should increase investment in research and development of carbon-reduction technology, zero-carbon technology, and carbon capture and storage for energy use and should make good use of these investments in the industry to decrease carbon intensity.

\section{Declarations}

